\title{
Qualitative study of medical students' experiences of a psychiatric attachment ${ }^{\dagger}$
}

\author{
Claire Archdall, ${ }^{1}$ Tanya Atapattu, ${ }^{1}$ Elizabeth Anderson ${ }^{2}$
}

The Psychiatrist (2013), 37, 21-24, doi: 10.1192/pb.bp.112.039065

${ }^{1}$ Avon and Wiltshire Mental Health Partnership NHS Trust, Bristol, UK; ${ }^{2}$ Higher Education Academy, York, UK

Correspondence to Claire Archdall (clairearchdall@hotmail.com)

First received 7 Mar 2012, final revision 24 Jul 2012, accepted 21 Aug 2012

\begin{abstract}
Aims and method This study utilised qualitative methods to explore medical students' experiences of a clinical attachment in psychiatry and examine the impact of these on career intentions. Fifteen 4th-year students from the University of Bristol were interviewed and their responses analysed.
\end{abstract}

Results Four key themes of role models, difference, stigma and career choice emerged from the analysis. Role models could be more influential than the specialty when choosing career options. Many students experienced psychiatry as being different to other specialties. For some this was a reason not to pursue psychiatry as a career but for others it was a positive aspect of the specialty. Stigma arose from a variety of sources, notably from medical students themselves.

Clinical implications These findings are relevant given the current recruitment problems in psychiatry and need to be considered in the planning and delivery of undergraduate medical education.

Declaration of interest None.
There have been numerous discussions about how to address the current recruitment problem in British psychiatry. This concern is not limited to the UK, with international research also highlighting a declining interest in the specialty. ${ }^{1}$ As a result there is a drive by the Royal College of Psychiatrists to increase interest at an undergraduate level in the hope that future students give consideration to psychiatry as a career.

Previous literature reports that medical students can develop more positive attitudes to psychiatry after completing a psychiatric clinical attachment. ${ }^{2-4}$ Positive attitudes post attachment have been linked to an increased intention to pursue psychiatry as a career. ${ }^{3}$ Despite these findings, the recruitment problem persists. This could partly be explained by studies which have found that these positive changes are not enduring and decline over a year. ${ }^{5}$

If undergraduate education is to be used effectively to influence recruitment, the factors which affect a student's experience of psychiatry and their career intentions need to be examined. For example, it is known that role models within medical school can influence a student's career choice, ${ }^{6}$ although there is limited knowledge on how medical students perceive and experience role models within psychiatry. A recent study has also suggested that the stigmatisation of psychiatry discourages medical students from pursuing the specialty as a career, ${ }^{7}$ and this requires further investigation.

This is one of a series of papers on recruitment in psychiatry. See also pp. 25-29 and pp. 30-32, this issue. Additional papers on this topic are due for publication in the February issue.
In this study, qualitative methods have been utilised to explore what it is really like for medical students to experience a clinical attachment in psychiatry and how this relates to their career intentions. It is hoped that the results will enable medical educators to optimise the benefits of psychiatric undergraduate education.

\section{Method \\ Participants}

Participants were chosen through criterion sampling and comprised all 4th-year medical students at the University of Bristol who had completed a clinical attachment in psychiatry in their third year. An independent administrator sent an email to the entire year which explained the study and included a participant information sheet. All students who expressed an interest in participating were contacted for interview.

\section{Data collection}

Each student was interviewed by either C.A. or T.A. The interviews took place at the University Academic Unit of Psychiatry or at a hospital base convenient to the student and lasted approximately $30-45 \mathrm{~min}$. A topic guide was devised by the authors of this paper and used for each interview. This guide covered students' attitudes to psychiatry and mental illness, their experience of the attachment and views on future careers. The interviews were digitally audio-recorded and students signed a consent form. 


\section{Ethics approval}

This study received ethical approval from the University of Bristol research ethics committee (ref. number 091016).

\section{Data analysis}

The interviews were transcribed verbatim by professional transcribers and the transcripts anonymised with removal of names of people and places. Standard methods of qualitative thematic analysis were used to analyse the transcripts. ${ }^{8}$ Analysis ran concurrently with data collection. The two principal researchers (C.A. and T.A.) familiarised themselves with the data and then started the process of coding where the data were organised into meaningful groups. Coding was done on an inductive basis which involved obtaining codes gradually from the data as it was collected. The two researchers coded independently and then worked together to develop a coding framework using Atlas ti software version 6 on Windows.

The lists of codes generated within the framework were analysed and sorted into broader groups. At this point the data were displayed via flow charts and diagrams to create a thematic map. This aided the identification of themes and examination of the relationships between codes and themes. The thematic map was discussed and reviewed with the third researcher (E.A.) and these discussions informed further analysis of the data and ongoing interviews. The whole process of analysis was repeated several times during data collection to allow further defining and refining of themes and ensure these accurately represented the data. Repeated re-examining and analysing of the data allowed us to develop explanations for the findings.

\section{Results}

In total, 15 students agreed to meet for interview (2 male and 13 female). Of these, two students were considering a career in psychiatry. From the analysis, four key themes emerged: role models, difference, stigma and career choice.

\section{Role models}

Many students commented on the importance of role models and how they influenced their experience of the clinical attachment. Several students said that a role model was a person whom they aspired to be:

'People you meet ... and you think, I'd like to be like them ... Someone who is successful and you'd like to be like that.'

'With any attachment . . . you take away from it depending upon how much you were sort of inspired by the people who taught you.'

Other qualities that students felt were important in a role model were enthusiasm, eagerness to teach and motivation. There was some suggestion that there may be fewer positive role models in psychiatry compared with other specialties:

'Some specialties are full of inspiring people . . . Psychiatry wasn't completely sold.'

The vast majority of students considered their role model to be the consultant to whom they were assigned during their attachment. As well as shaping their view of the specialty, these consultants could influence their experience:
'The people that had a consultant who regularly followed them up and took them places would get more out of it.'

For one student, it was the junior rather than senior doctor who was the main role model.

Role models did not always influence students in a positive way. One student spoke of a particularly negative role model:

'One of our teachers actually really put us off. He was sort of weird and said things like, "Well gastro doctors only want to do that because they like orifices and their mother's vagina", and that made us feel really uncomfortable.'

Some students commented that role models could even be more influential than the specialty itself in terms of their enjoyment of the attachment and choosing their career. This was true of all specialties, not just psychiatry. One student said of a general practice (GP) attachment:

'Some people just don't enjoy GP because of who they've got and that destroys the whole thing for them.'

\section{Difference}

Almost all students noticed that psychiatry seemed different to other areas of medicine and expressed this in various ways. At the beginning of the attachment, students observed that the location of psychiatry was separate:

'The hospitals are apart . . shutting away something that is different.'

Also, the approach to work was different compared with other specialties. For example, students observed that patients could choose whether they wished to attend their own ward round and that ward rounds often seemed to focus on social issues 'rather than the medical conditions'. In addition, nurses wore plain clothes instead of a uniform. The experience with patients themselves was also different, in that some students reported feeling scared, intimidated or finding the work 'draining':

'I think it was quite an emotional burden . . . seeing people at the lowest points in their life.'

Difference was also discussed in terms of treatment outcomes:

'A lot of [other students] said to me that they decided during the placement that they didn't want to be a psychiatrist because you can't fix people and you're not actually curing anyone.'

'It definitely comes across [as different] to other professions where you completely achieve remission ... from their illness or a broken leg or something.'

Some students experienced the differences in a positive way, feeling privileged to ask patients in-depth personal questions and finding it 'refreshing to think in a different way'. Others felt unprepared and were unsure of how to manage the differences, especially with regard to communication and history-taking:

'Do you tell someone that what they think isn't true, you know, if they're hallucinating . . . or do you go along with it?...It did feel we were quite underprepared and it was like, "Okay - go!",

\section{Stigma}

Students found that stigma arose from a wide variety of sources, including from other medical students. Those who had already completed their attachment sometimes joked 
about the specialty and portrayed psychiatry as a particularly 'dossy' placement where you could 'slack off'. At times, students felt a pressure to be negative towards psychiatry regardless of their actual experience of the attachment:

'The year above ... say oh they did psychiatry, they only went in one day a week ... and I think some of it [is] cos they feel they should [say that], it's got this stigma attached to it . . . I think it's a good placement and people should do it but I guess peer pressure [means] you have to say "Oh psych, urgh".

Another student wondered whether the humorous remarks sometimes made about psychiatry were linked to a student's maturity:

'I don't know if it's just people like, sort of make flippant jokes about things, just trying to make people laugh, again probably because they are quite young still.'

Students found that stigma could also arise from within psychiatry itself, commenting that staff on the wards sometimes displayed negative attitudes towards patients:

'He's just a pain . . . so we're just going to give up.' [Nurse talking about patient]

Doctors from other specialties could also be a source of stigma:

'They ask what all the students want to do ... if anyone ever says "oh I think I might do psychiatry" they are always like "Oh no" or something like that.

Some students reported having negative perceptions of psychiatry and mental illness before starting their attachment because of misunderstandings in the media. This was coupled with many commenting that compared with other specialties, prior to starting their attachment, they did not have much understanding of the role of a psychiatrist.

\section{Career choice}

The three aforementioned themes were all associated with students' career intentions:

'If you think "I can’t help people”, why would I want to go into it?'

Some of the differences within psychiatry, such as the emotional burden of the work and its focus on seemingly non-medical issues, were quoted by students as reasons for not considering a career in psychiatry. In contrast, one student found that the differences positively influenced their decision to pursue psychiatry:

'Afterwards, I was almost certain that I wanted to do a career in psychiatry. I didn't think that there would be anything else I would find as interesting ... It's like the continuity and the building up of more of a relationship which you don't get in other areas of medicine. I think I would find that very rewarding.'

Several students emphasised the importance of role models when making career choices:

'I find as I go through, the people I meet, that kind of influences what you do probably more than the actual specialty ... it's kind of you want to be like them more than what they do.'

Some students wondered whether the third year was the most appropriate time to undertake an attachment in psychiatry in terms of career choice:
'I would probably be less intimidated now because I feel like my communication skills are better . . . I have had a lot more experience... in all the different medical specialties that we have done ... . at the time, we didn't know how to talk to any patient really ... let alone somebody with like a mental health problem.'

\section{Discussion}

This study demonstrates the many complexities faced by students before, during and after a psychiatry clinical attachment. The four key themes of role models, difference, stigma and career choice were found to interlink and impact on each other.

It is known that exposure to role models in a particular clinical area is associated with medical students' choice of clinical field. ${ }^{6}$ Supporting this finding, students in this current study reported that inspiring, motivating or enthusiastic role models would encourage them to pursue psychiatry as a career. Indeed for some students, role models were more influential than the specialty itself. Conversely, a negative role model could discourage a student from a career in psychiatry. This study raised the possibility that there are fewer positive role models within psychiatry compared with other specialties. There is limited literature to confirm whether this is a view held within other medical schools.

The differences that students experienced within psychiatry tended to be perceived in a negative way. It is believed that an undesirable perception of difference can feed into the generation of stigma. ${ }^{9}$ In this study a number of sources of stigma were identified which could have been reinforced by the students' negative perceptions of difference within the specialty. This is interesting in light of the finding that a powerful source of stigma was from other medical students who had already undertaken an attachment in psychiatry. There seemed a pressure on a student to portray psychiatry in a negative way or make 'flippant jokes', even if they had had a positive experience of the specialty. The strong influence of narratives passed down through generations of students has been described by Hafferty in his study of cadaver stories. ${ }^{10}$

The humour and peer pressure described earlier demonstrate the challenges that medical students face when undertaking an attachment in psychiatry. These challenges are likely to be compounded by feeling unprepared for the differences which several students described. This raises the issue of whether the third year is the optimal time to manage these differences, a point made by some students themselves. It could be that negatively directed humour is a way for an inexperienced student to deal with a feared difference. Some students may 'slack off' as a way of avoiding this difference altogether. It is worth noting that certain negative perceptions of difference such as psychiatry being emotionally draining were directly quoted as reasons for not wanting to pursue a career in the specialty.

It is interesting to consider why differences within psychiatry can be challenging to the medical student. In her study of negotiating professional identities, ${ }^{11}$ Lyn Monrouxe describes medical students arriving at medical school with understandings about what it is to be a doctor derived from 
master narratives within society. These narratives are then challenged as students progress through their training. It could be hypothesised that the differences within psychiatry are at odds with the students' concepts of their identity as a doctor. Professional identity develops throughout medical school alongside clinical knowledge. ${ }^{12}$ If, as at University of Bristol Medical School, a psychiatry attachment is undertaken early in the clinical years, the challenge students face to their developing identities may be greater.

However, the experience of difference was not always negative and, indeed, was refreshing for some. The students who perceived the differences in a positive way were more likely to consider psychiatry as a career after the attachment, which is consistent with previous quantitative studies that have found that positive experiences of psychiatry influence career choice. ${ }^{3}$ It would be useful to investigate whether it is the characteristics of the students themselves or external factors such as role models that enabled them to perceive difference in this way.

\section{Limitations}

A potential limitation of this study was the self-selection of the students which could have introduced bias. The findings do, however, show a variation in experience and opinion. The students' responses may have been affected by the fact that the two researchers conducting the interviews were both psychiatrists. To minimise this, students were reassured that the interviews were confidential and anonymised. The expression of both positive and negative views implied that they felt able to be honest. In this study, students from only one medical school were interviewed. However, the findings do support what is known within the literature about students' experiences of psychiatry, suggesting the results are generalisable.

\section{Conclusions and implications}

A student's experience of an attachment in psychiatry is complex. It is influenced by role models, who may be of more importance to the student than the specialty itself in terms of career choice. Many students experience psychiatry as different to other specialties. In some cases this feeds into stigma, but this does not always transpire, and sometimes the difference can be positive. Stigma can come from a variety of sources, notably from other medical students.

These findings need to be considered in light of the known difficulties in recruitment to psychiatry. Medical educators could consider the following points when planning or delivering undergraduate psychiatric education.
1 Increased awareness of the importance and responsibility of role models. There is an increased focus towards training doctors to become better teachers, and this may need to incorporate education on being a role model.

2 Exploring the differences in psychiatry with students to help them to feel better prepared and less challenged by these. This could help reduce the negative perceptions of psychiatry that appear to be passed down through medical school.

3 Increased recognition and exploration of the sources of stigma that exist, especially within medical students themselves and the psychiatry profession.

4 Consideration of timing of the psychiatry attachment in the curriculum.

\section{About the authors}

Dr Claire Archdall is an ST6 in general adult psychiatry and Dr Tanya Atapattu is an ST6 in old age psychiatry, Avon and Wiltshire Partnership NHS Trust, Bristol, UK. Elizabeth Anderson is Discipline Lead for Medicine and Dentistry at the Higher Education Academy, York, UK.

\section{References}

1 Wigney T, Parker G. Factors encouraging medical students to a career in psychiatry: qualitative analysis. Aust N Z J Psychiatry 2008; 42: 520-5.

2 Glynn S, Reilly M, Avalos G, Mannion L, Carney PA. Attitudinal change toward psychiatry during undergraduate medical training in Ireland. Ir J Psychol Med 2006; 23: 131-3.

3 McParland M, Noble I, Livingstone G, McManus C. The effect of a psychiatric attachment on students' attitudes to and intention to pursue psychiatry as a career. Med Educ 2003; 37: 447-54.

4 Singh SP, Baxter $\mathrm{H}$, Standen $\mathrm{P}$, Duggan $\mathrm{C}$. Changing the attitudes of tomorrow's doctors towards mental illness and psychiatry: a comparison of two teaching methods. Med Educ 1998; 32: 115-20.

5 Baxter H, Singh SP, Standen P, Duggan C. The attitudes of tomorrow's doctors' towards mental illness and psychiatry: changes during the final undergraduate year. Med Educ 2001; 35: 381-3.

6 Wright S, Wong A, Newill C. The impact of role models on medical students. Gen Intern Med 1997; 12: 53-6.

7 Curtis-Barton MT, Eagles JM. Factors that discourage medical students from pursuing a career in psychiatry. Psychiatrist 2011; 35: 425-9.

8 Braun V, Clarke V. Using thematic analysis in psychology. Qual Res Psychol 2006; 3: 77-101.

9 Smith M. Stigma. Adv Psychiatr Treat 2002; 8: 317-23.

10 Hafferty FW. Cadaver stories and the emotional socialization of medical students. J Health Soc Behav 1988; 29: 344-56.

11 Monrouxe LV. Negotiating professional identities: dominant and contesting narratives in medical students' longitudinal audio diaries. Current Narratives 2009; 1: 41-59.

12 Monrouxe LV. Identity, identification and medical education: why should we care? Med Educ 2010; 44: 40-9. 